\title{
What are the
}

\section{challenges}

\section{facing the dental}

\section{nurse profession?}


What made you choose your dissertation subject?

My MSc related to my area of professional practice: dental nursing. Therefore, I decided to complete my dissertation on a subject pertaining to dental nurses. I had always wondered why you rarely see dental nurses represented in positions of influence, where policy and decisions that are made can affect the profession as a whole. I was also interested in the perceived ceiling for dental nurse professional progression and how this affects the morale and empowerment of the profession as a whole.

What do you think are the biggest issues facing dental nurses in 2021? I think that one of the issues that dental nurses (DNs) are facing in 2021 is one that has been plaguing dental nurses since compulsory registration was introduced: pay. In the view of the government we are classed as professionals, yet, the pay does not seem to match the professional title. The word 'dental nurse' is a protected term and covered by law as a profession. DNs have been regulated by the GDC since the Professions Complementary to Dentistry Regulations Order of Council $2006^{1}$ made registration compulsory in 2008 .

In my opinion, it appears that there is a false narrative being aimed at DNs with regards to the pay they could earn, and how paying for post registration qualifications is another way that they can get an increase in pay. I believe this is not the case. This has led to disillusionment of DNs and some of them have decided that they want to leave the profession, or become dental hygienists and dental therapists, as this seems to be a way to earn more money.

The 2020 Annual Salary Survey by the BADN was completed during October and December of 2020 and the results were published in March 2021. The full findings can be accessed on the BADN website; this is a selection of their findings:

1. $99 \%$ of respondents were female with less

than $1 \%$ each male, identify as other, or prefer not to say

2. The majority of respondents were living with a partner and children, and nearly a third (31\%) were the primary earner in the household (vs $23 \%$ in 2013)

3. Just under two-thirds of respondents worked more than 35 hours per week

4. The majority of respondents earned between $£ 10,000$ and $£ 20,000$

5. More than half of respondents (55\%) had to pay all (51\%) or part (4\%) of their GDC registration fee; nearly three-quarters $(71 \%)$

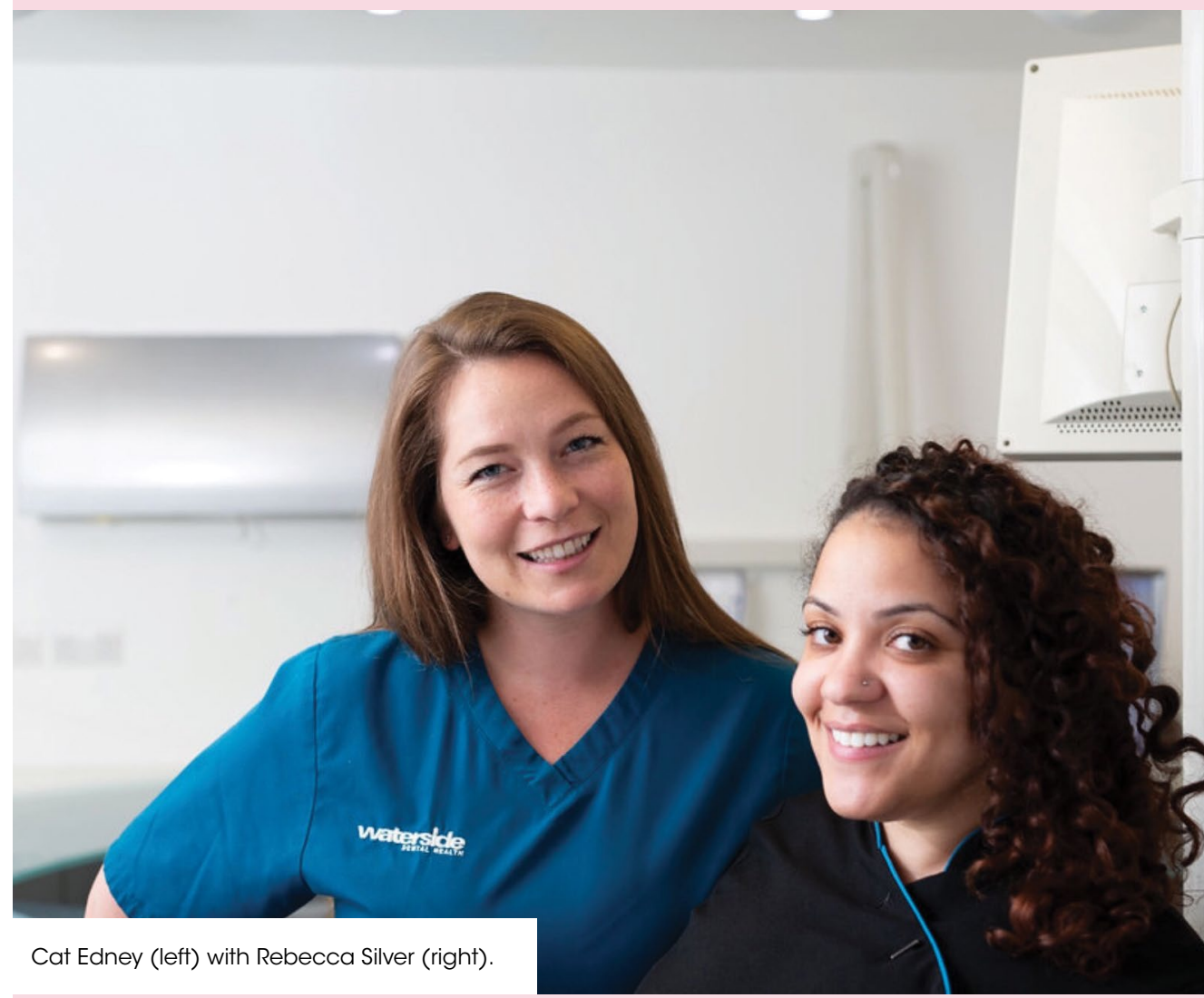

\section{'I had ahvays wondered why you rarely}

\section{see dental nurses represented}

\section{in positions of influence, where policy and decisions that are made can affect the profession as a whole.'}

all (50\%) or part (21\%) of their CPD costs; $87 \%$ were not allowed paid protected time off to complete their CPD requirements; and, of those who were BADN members, $91 \%$ had to pay their own BADN membership fee

6. $16 \%$ of respondents have a second job. Of those, nearly half ( $48 \%$ ) say it is necessary to meet their basic living costs, a third (35\%) to provide a better standard of living and $10 \%$ to pass on their skills. Other reasons include additional experience, and to help out during lockdown

7. Of those furloughed during $2020,70 \%$ received $80 \%$ of their normal salary. Of those furloughed during 2020,27\% were paid less than the statutory $80 \%$ of their salary by their employer; and $14 \%$ of those furloughed were not paid at all.

(BADN Salary Survey 2020, 2021..2)
Jacqui Elsden, current BADN president, started the 'Recognition of Dental Nurses' Contribution to Dentistry' campaign. The campaign aims to ensure that DNs get the recognition and pay that they deserve as professionals. $^{3}$

The pandemic has also made a lot of people reassess their priorities, not just within dentistry. Some people have now made the decision that they want to spend more with family and friends. Some are fighting to receive the pay they deserve.

What would you like to see more of in the dental nursing profession?

I would like to see more DNs showcased and appreciated more within dentistry as a whole. DNs already offer support, guidance and care to other DNs. It would be nice to see this in 
the profession as a whole, especially with regards to dental publications (not including the British Dental Nurses' Journal, Dental Nursing or BDJ Team), as I am very much aware that DNs are supported and represented in them.

Also, I feel some eCPD courses that are targeted to the profession are out of the price range of many DNs and that is a shame. I understand that certain courses will be targeted to the clinicians as are out of the scope of a DN. But if the teaching on the courses includes areas where four handed dentistry is mentioned, or the knowledge gained would affect the DNs once the clinicians start to implement new processes to the dental surgery, why can't a DN attend, even for a couple of hours and at a reasonable cost?

\section{What options are there for dental nurses who want to further their career?}

In my opinion, currently not as many compared to other registrant groups. Post registration certificates are advertised, promoted and encouraged; but after obtaining these, application in practices is limited and not utilised as much as they have the potential to be. This is not universal however, and there are many DNs who have obtained post qualification certificates who have received financial rewards as well as increasing their responsibility and roles within their practices.

Currently, the post registration certificates that a DN can obtain, through NEBDN (National Examining Board for Dental Nurses) are:

- Dental Implant Nursing

- Dental Radiography

- Dental Sedation Nursing

- Fluoride Varnish Application

- Oral Health Education

- Orthodontic Dental Nursing

- Special Care Dental Nursing.

Some DNs finance these courses entirely on their own, only to realise that they may not reap financial rewards after qualifying. ${ }^{4}$

However, there is now an increase in the number of institutions offering dental nurse degrees at different schools and different degree levels. I would recommend that if this is a career path that you wish to do, I would research universities and their requirements. Each awarding body will have their own requirements based on the level of the degree, and what previous qualifications are required. UCAS (Universities and Colleges Admissions Service in the UK) are also very helpful and will be able to answer questions with regards to awards and entry requirements.

In my opinion and experience, the career paths of dental nurses appear to have a ceiling. And if not a limit, then a 'side step' into practice management and treatment coordinators. Normal career progression for DNs include but are not limited to:

- A post registration certificate

- Applying for dental hygiene and therapy

- Moving towards treatment co-ordinating or practice management

- Teaching and assessors for DNs. presents to the profession and the wider public that DNs can never become dentists. This isn't true, as applying to a dental school is different from finding a job in a dental practice as a DN role and so are the entry requirements.

\section{How can dental nurses be better} recognised in the profession?

There are already some DNs who are recognised within the profession and have jobs in academia and within other areas, such as the NHS, CQC, GDC and within dental

\section{'Being recognised and respected doesn't need to be complicated or expensive.}

\section{It can be as simple as ensuring that} every time you refer to a dental nurse
their protected title is used.'

These pathways are not universal, and cannot be generalised and applied to the DN profession as a whole. These pathways are purely my own experiences. However, I am also aware that a number of DNs don't fall into these categories - although I do believe that it may be different for a NHS or community DN compared to the 'high street practice' DN. And I am also aware that life doesn't always go the way we plan, and that circumstances change for everyone, and therefore careers sometimes have to take a back seat to life.

I do feel however, that whenever careers and pathways are discussed in relation to DNs, there are not many I have seen that include becoming a dentist as one of them. Even in the media produced by the NEBDN and in their most recent prospectus, the limit of progression for a DN stops at dental hygiene or dental therapy (see https:// www.nebdn.org/app/uploads/2021/07/ Prospectus-2021-July.pdf). Of course I love my profession, and I have no desire to become a clinician, but I do find it puzzling that becoming a dentist is not seen as job progression for DNs and I wonder why that is. Dental hygiene and dental therapy appear to be promoted as the highest progression any DN can make. Whilst I don't wish to be a clinician (dentist or dental hygienist or dental therapist), I do feel that this subconsciously public health just to name a few. So I don't feel that individuals are not recognised, more that the dental nurse profession is not recognised and valued as other registrant groups as a whole. And the BADN and Society of British Dental Nurses (SBDN) presidents and representatives are invited to consultations at a national level with other groups such as the GDC and British Dental Association (BDA).

Being recognised and respected doesn't need to be complicated or expensive. It can be as simple as ensuring that every time you refer to a DN their protected title is used. We are dental nurses, not registered nurses. Registered nurses have their own protected title. Currently the title 'nurse' isn't a protected title and anyone can call themselves a nurse if they wish. The respect of calling DNs by their title may seem small and trivial, but when you've spent so long to get there, it can become demoralising if you are constantly not recognised as such.

It can also include having an appreciation for the amount of knowledge we actually have to learn before we can sit our exams and gain entry onto the GDC register. Dental students and dental hygiene and dental therapy students are in a dental hospital full time whilst they are undergraduates. DNs normally have a full or part time job, working for minimal pay, completing their Records of Experience (ROE), potentially 
supporting their family and many haven't been in structured education for some years. I left college at the age of 18 and gained my GDC number by the time I turned 21. My experience isn't the experience of all DNs, but even I found working full time and learning again difficult and I wasn't even out of structured education for long. There is a perceived lack of respect and understanding for how much DNs are expected to do and learn whilst they are trainees. Clinicians appear to be given grace, but not DNs. I advise any clinician to look at the DN curriculum and try to remember what it felt like as a student. The difference is that DNs do it in a non-educational setting.

An employee who feels valued will always do more for their employer, and value is not necessarily translated to money. It is saying thank you at the end of the day, or acknowledging your DN by their name once the patient is in the surgery.

It is sharing positive reviews with the team and DNs. It is respecting their knowledge as a DCP and registrant. If you allow your DNs to provide post-operative feedback to patients then acknowledge that they know what they are talking about. Dr Anish Shah, Consultant Oral Surgeon, used to allow me to provide post-operative instructions to oral suregry patients. He trusted me to know when to pass on questions to him, but also always acknowledged that the information that I provided was correct, and was corroborated by himself; and he would call me by my name.

Being empowered is an important component of a working life, for everyone involved with dentistry as a profession! Empowerment translates to confidence. Making sure that your team is made up of confident DNs can be life changing. The workload is then distributed more evenly. A confident DN can be a first point of contact for a patient depending on their need. I worked five days a week (whilst completing my FdSc and MSc), but I still gave my work email address out to nearly all of my patients. I can answer an email quicker than a clinician, who may be working at other sites and practices, can. Most emails I could answer without input from clinicians, as these were normally related to appointments and post-operative instructions. Yet I knew what my limit was as a DN and would forward the more difficult emails to the relevant clinician. This meant that the replies from the clinicians were quicker, because they didn't have to answer every email from patients. This also allowed me to build amazing patient rapport. I was also lucky that I could share knowledge from my degree courses with my colleagues.
I love the sound of my own voice, but I know that I never felt that I couldn't ask a question or talk about what I learnt. Sometimes, even the patients learnt new knowledge - usually when they were in the middle of a two-hour root canal, with a rubber dam and couldn't leave!

\section{Anything you would like to add?}

There is a move towards DCP groups taking on more clinical work to address the everchanging oral health needs of the public; however, as many dental professionals in positions of influence are dentists, there appears to be an imbalance of DCP groups being able to actively change and be involved with aspects specifically pertaining to their profession. My hope for the future is that this imbalance can be addressed by more RDNs looking to further their education and awareness of dental public health and policy and the profession empowering RDNs to look at these career paths as an attainable and worthwhile investment.

\section{References}

1. Council for Regulatory Excellence. Protecting the public from unregistered practitioners. Tackling misuse of protected title. February 2010. Available at: https:// www.professionalstandards.org.uk/docs/ default-source/publications/policy-advice/ tackling-misuse-of-protected-title-2010. pdf?sfvrsn=d8c77f20_10 (accessed 31 July 2021).

2. British Association of Dental Nurses. BADN salary survey 2020. March 2021. Available at: https://www.badn.org.uk/ common/Uploaded\%20files/2020\%20 Salary\%20Survey\%20-\%20FULL\%20 REPORT.pdf (accessed 31 July 2021).

3. Elsden J. 'Join our campaign to safeguard the dental nurse workforce.' $B D J$ Team 2021; 8: 4. Available at: https://doi. org/10.1038/s41407-021-0656-2 (accessed 31 July 2021).

\section{Useful resources}

1. UK Government. Organisations, Ofqual. Available at: https://www.gov. uk/government/organisations/ofqual (accessed 31 July 2021).

2. UK Government. What qualification levels mean. Available at: https://www.gov.uk/ what-different-qualification-levels-mean (accessed 31 July 2021).

https://doi.org/10.1038/s41407-021-0781-y

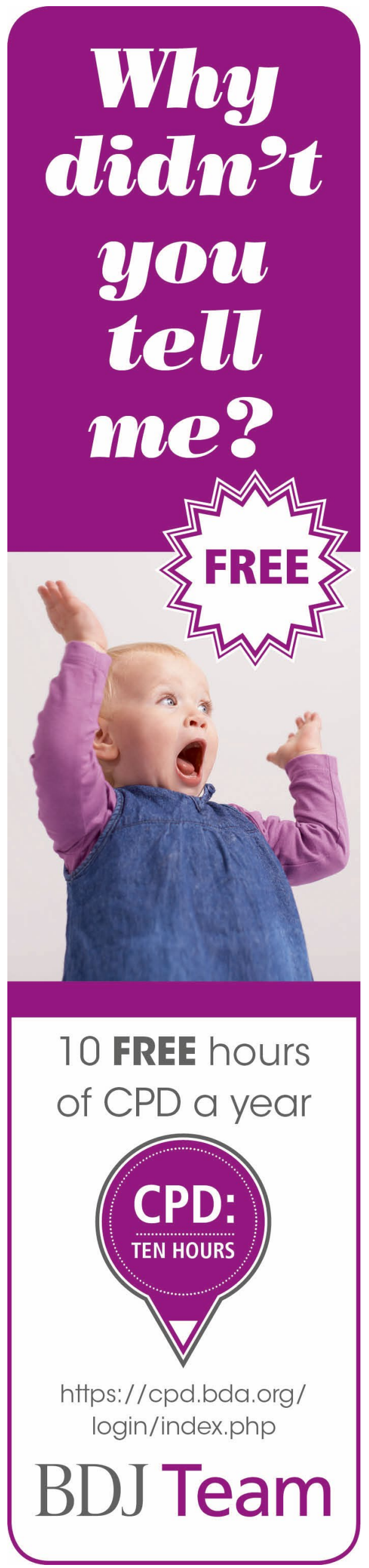

